\title{
The Effect of Silicon Orientation on Thickness and Chemical Bonding Configuration of $\mathrm{SiO}_{x} \mathrm{~N}_{y}$ Thin Films
}

\author{
M. M. Ismael \\ Physics Department, College of Science, University of Salahaddin, Erbil, Kurdistan, Iraq \\ E-mail address: mahemuhsen@yahoo.com
}

\begin{abstract}
Fourier Transform Infrared (FTIR) Spectroscopy and Capacitance-Voltage measurements are used to characterize the chemical bonding configuration and crystallographic orientations for $\mathrm{SiO}_{\mathrm{x}} \mathrm{N}_{\mathrm{y}}$ thin films grown by glass assisted $\mathrm{CO}_{2}$ laser. FTIR spectra detected the $\mathrm{Si}-\mathrm{O}$ and $\mathrm{Si}-\mathrm{N}$ strongest absorption bands are close to each other at wave number in the range $\left(700-1000 \mathrm{~cm}^{-1}\right)$ depending on silicon substrates, and Si-O stretching bond at wave number around $\left(\sim 1088.285 \mathrm{~cm}^{-1}\right)$ with a FWHM of $73.863 \mathrm{~cm}^{-1}$ for the two samples, the presences of hydrogen impurities like $\mathrm{Si}-\mathrm{H}$ and N-H in the films were also identified and calculated. From C-V measurement film thickness were calculated and found to be 19.2 and $17.2 \mathrm{~nm}$ for $\mathrm{SiO}_{\mathrm{x}} \mathrm{N}_{\mathrm{y}} / \mathrm{Si}(111)$ and $\mathrm{SiO}_{\mathrm{x}} \mathrm{N}_{\mathrm{y}} / \mathrm{Si}(100)$ respectively. From the flat band voltage of -5.4 and -1.3 measured the two samples, their interface trap densities were found to be $1.4 \times$ $10^{13}$ and $1.57 \times 10^{13} \mathrm{ev}^{-1} \cdot \mathrm{cm}^{-2}$ respectively.
\end{abstract}

Keywords: Glass assisted $\mathrm{CO}_{2}$ laser; Silicon substrate; $\mathrm{SiO}_{\mathrm{x}} \mathrm{N}_{\mathrm{y}}$ Thin Film

\section{INTRODUCTION}

From the beginning of this century, oxynitride films are being examined as potential materials in replacing $\mathrm{SiO}_{2}$ in metal-oxide-semiconductor (MOS) devices [1]. There oxynitride are considered as a very promising material for both optical and electrical applications due to the possibility of tailoring the properties there oxynitride by acting on their elemental composition. However their physical and electro-optical properties are related to the compositions, morphology and structure of the films.

These materials are transparent in the visible range and their refractive index can vary from 1.46 to 2.0 and dielectric constant from 3.9 to 10 depending upon the nitrogen and oxygen contents $[2,3]$. However dielectric and semiconductor materials are compatible with their micro and optoelectronics which has been conducted recently [4]. In this paper, attempts are made first to the use of the $\mathrm{C}-\mathrm{V}$ technique to measure the changes in $\mathrm{SiO}_{\mathrm{x}} \mathrm{N}_{\mathrm{y}}$ films thickness grown by glass assisted $\mathrm{CO}_{2}$ laser, the films Chemical bonding configurations are analyzed by the use of FTIR spectroscopy. 


\section{PREPARATION METHODS}

The p-type Si substrates with the surface planes (111) and (100) and dimensions of (1.5 $\mathrm{cm} \times 1.5 \mathrm{~cm}$ ) were used. Substrate resistivities in the range of were $1-30 \Omega \cdot \mathrm{cm}$. The samples were cleaned from organic residues using wet RCA cleaning method, and subsequently rinsed in diluted HF solution for removal the native $\mathrm{SiO}_{2}$. The final rinse was in DI water before loading the sample substrate in the reaction chamber. Nitrogen gas was used for purging the chamber before starting the laser growing process. Ammonia and oxygen gases were used as main sources for growing thin $\left(\mathrm{SiO}_{\mathrm{x}} \mathrm{N}_{\mathrm{y}}\right)$ films on the silicon substrate. The experimental apparatus used in the growing process are shown in Fig. 1. It consists of a continuous wave $\mathrm{CO}_{2}$ laser (Maximum power $80 \mathrm{~W}$ and $\lambda=10.6 \mu \mathrm{m}$ ), the laser beam was directed through $\mathrm{NaCl}$ window into the chamber using a copper mirror fixed at $45^{\circ}$. The nitridation oxidation processes were as the following; the silicon substrate was located on the Pyrex plate of about $3 \mathrm{~mm}$ thick which is fixed on the glass grains to absorb $\mathrm{CO}_{2}$ laser beam. The Pyrex glass and silicon substrate are fixed inside the graphite crucible, the substrate temperature made to be remain constant during the growing process. High purity $\mathrm{NH}_{3}$ and $\mathrm{O}_{2}$ were used as reactive gases and the premixed are just before injecting to the reaction chamber. The oxygen gas was introduced in to the chamber at flow rate of $1.5 \mathrm{Lit} / \mathrm{min}$ following by ammonia with the pressure of 0.1 bar injected into the chamber. The K-type thermocouple is fixed in a small hole underneath the sample whereas substrate kept at constant temperature. The samples remain in the chamber at its temperatures during the processing for $\sim 60$ minutes. All the process is conducted at an atmospheric pressure. Thin thicknesses and some electrical properties of the films were determined by Capacitance-Voltage measurements. Chemical bonding configurations were determined by using Fourier Transform Infrared Spectroscopy (FTIR) immediately after deposition. For the C-V measurement, Metal/silicon oxynitride/silicon capacitors were formed by thermal evaporation method for Al dots through a metal mask on the surface while continuous $\mathrm{Al}$ was evaporated on the Si backside of nearly $2000 \AA$ thick with the substrate temperature of $350^{\circ} \mathrm{C}$ and kept 30 minutes as the annealing process.

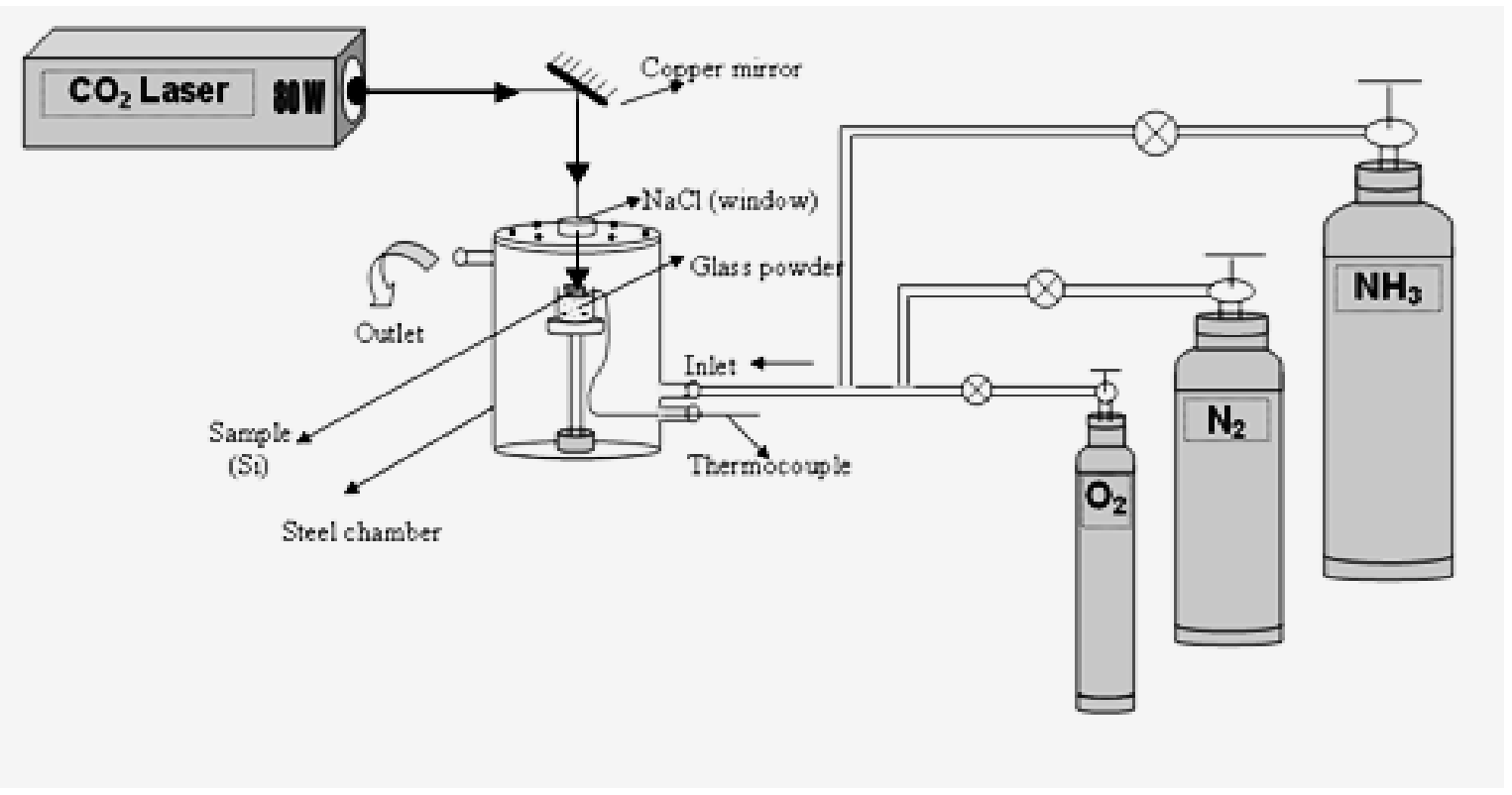

Fig. 1. Schematic diagram of glass assisted $\mathrm{CO}_{2}$ laser techniques. 


\section{1. FTIR spectroscopy}

Infrared energy is emitted from a glowing black-body source. This beam pass through an aperture which controls the amount of energy presented to the sample and ultimately to the detector. The interferometer produces a unique type of signal which has all of the infrared frequencies "encoded" into it. The resulting signal is called an interferogram (contains intensity information about all frequencies present in the infrared beam).

Because this signal cannot be interpreted directly, a means of "decoding" the individual frequencies is required. This can be accomplished via a well-known mathematical technique called the Fourier transformation.

The resulting spectrum shown in Figure 2, represents the molecular absorption and transmission. The spectrum peaks are represents molecular fingerprints of the sample, the absorption peaks are correspond to the frequencies of materials atomic vibrations.

FTIR characterizations of the samples under investigation were performed using (FTIR300, from Mattson instruments) spectrometer which operates in the mid-infrared region 400$4000 \mathrm{~cm}^{-1}$.

\section{2. C-V measurement}

For producing the saw tooth wave form of $2 \mathrm{~V}_{\mathrm{p.p}}-4 \mathrm{KHz}$ [FG 502-11 MHz], function generator is used for uncharged samples, the $\mathrm{C}-\mathrm{V}$ characteristic scan can give all three different states (accumulation to inversion) region, which shows.

For measuring high frequency $(\mathrm{C}-\mathrm{V})$ characteristic, the Fluke PM 6306 programmable automatic RCL meter was used it can measure the device capacitor and conductance at any bias voltage and at any signal frequency. The internal bias voltage of $50 \mathrm{mV}$ was used in the system according to the scanned frequency generated for $1 \mathrm{MHz}$ as a test signal.

\section{RESULTS AND DISCUSION}

Silicon oxynitride $\left(\mathrm{SiO}_{\mathrm{x}} \mathrm{N}_{\mathrm{y}}\right)$ films exhibit properties that fall somewhere between that of silicon oxide and those of silicon nitride films and have diverse applications in microelectronics. Fig. 2 and Fig. 3 shows the FTIR analysis of $\left(\mathrm{SiO}_{\mathrm{x}} \mathrm{N}_{\mathrm{y}}\right)$ films for substrate orientations of $\mathrm{Si}(111)$ and $\mathrm{Si}(100)$ respectively. IR studies of $\mathrm{SiO}_{2}$ and $\mathrm{Si}_{3} \mathrm{~N}_{4}$ materials have shown that the Si-O and Si-N strongest absorption bands are close to each other: $1060 \mathrm{~cm}^{-1}$ for $\mathrm{Si}-\mathrm{O}$ in $\mathrm{SiO}_{2}$, and $890 \mathrm{~cm}^{-1}$ for $\mathrm{Si}-\mathrm{N}$ in $\mathrm{Si}_{3} \mathrm{~N}_{4}$. Therefore, these bands could overlap in $\mathrm{SiO}_{\mathrm{x}} \mathrm{N}_{\mathrm{y}}$ films [5].

The large absorption band located between 700 and $1000 \mathrm{~cm}^{-1}$ shown in Figure 2 and 3 is a superposition of several overlapping modes of $\mathrm{Si}-\mathrm{O}$ and $\mathrm{Si}-\mathrm{N}$ bonds [6]. The absorbance peak of Si-N wagging mode near $460 \mathrm{~cm}^{-1}$ is a predominant spectral features $[7,8]$ of silicon oxynitride films. This peak is clearly appeared in oxynitride films at $\sim 462 \mathrm{~cm}^{-1}[6,9]$ while the absorption band assigned at $1080 \mathrm{~cm}^{-1}$ is associated with the Si-O asymmetrical stretching mode $[10,11]$.

The increase in the wave number can be explained through the presence of $\mathrm{Si}-\mathrm{N}$ bonds. The full width at half maximum (FWHM) found to be equal for both sample spectrum peaks and they are equal to $73.863 \mathrm{~cm}^{-1}$. The appearance of a shoulder in the range 1147.79 to $1290.81 \mathrm{~cm}^{-1}$ band, are correspond to $\mathrm{Si}-\mathrm{O}$ stretching vibration modes, and it is related to the out of phase motion of oxygen atoms [12]. 
Table 1. Full bonds which appear in the films with silicon substrate.

\begin{tabular}{|c|c|c|c|c|c|c|c|}
\hline $\begin{array}{c}\text { Silicon } \\
\text { Substrate }\end{array}$ & $\begin{array}{c}\text { Si-N } \\
\text { Wagging } \\
\text { bond } \\
\left(\mathrm{cm}^{-1)}\right.\end{array}$ & $\begin{array}{l}\text { Si-Si } \\
\text { Bond } \\
\left(\mathbf{c m}^{-1)}\right.\end{array}$ & $\begin{array}{c}\text { Si-N-O } \\
\text { Stretching } \\
\text { Bond } \\
\left(\mathrm{cm}^{-1)}\right.\end{array}$ & $\begin{array}{c}\text { Si-O } \\
\text { Stretchng } \\
\text { Bond } \\
\left(\mathrm{cm}^{-1)}\right.\end{array}$ & $\begin{array}{c}\text { N-H } \\
\text { Bending } \\
\text { Bond } \\
\left(\mathbf{c m}^{-1)}\right.\end{array}$ & $\begin{array}{c}\text { Si-H } \\
\text { Stretching } \\
\text { Bond } \\
\left(\mathbf{c m}^{-1)}\right.\end{array}$ & $\begin{array}{c}\text { N-H } \\
\text { Stretching } \\
\text { Bond } \\
\left(\mathrm{cm}^{-1)}\right.\end{array}$ \\
\hline $\mathrm{Si}(111)$ & 461.83 & 610.70 & $700-1000$ & 1089.37 & 1457.33 & 2364.58 & 2916.71 \\
\hline $\mathrm{Si}(100)$ & 461.52 & 611.05 & $700-1000$ & 1087.26 & 1454.95 & 2358.05 & 2918.80 \\
\hline
\end{tabular}

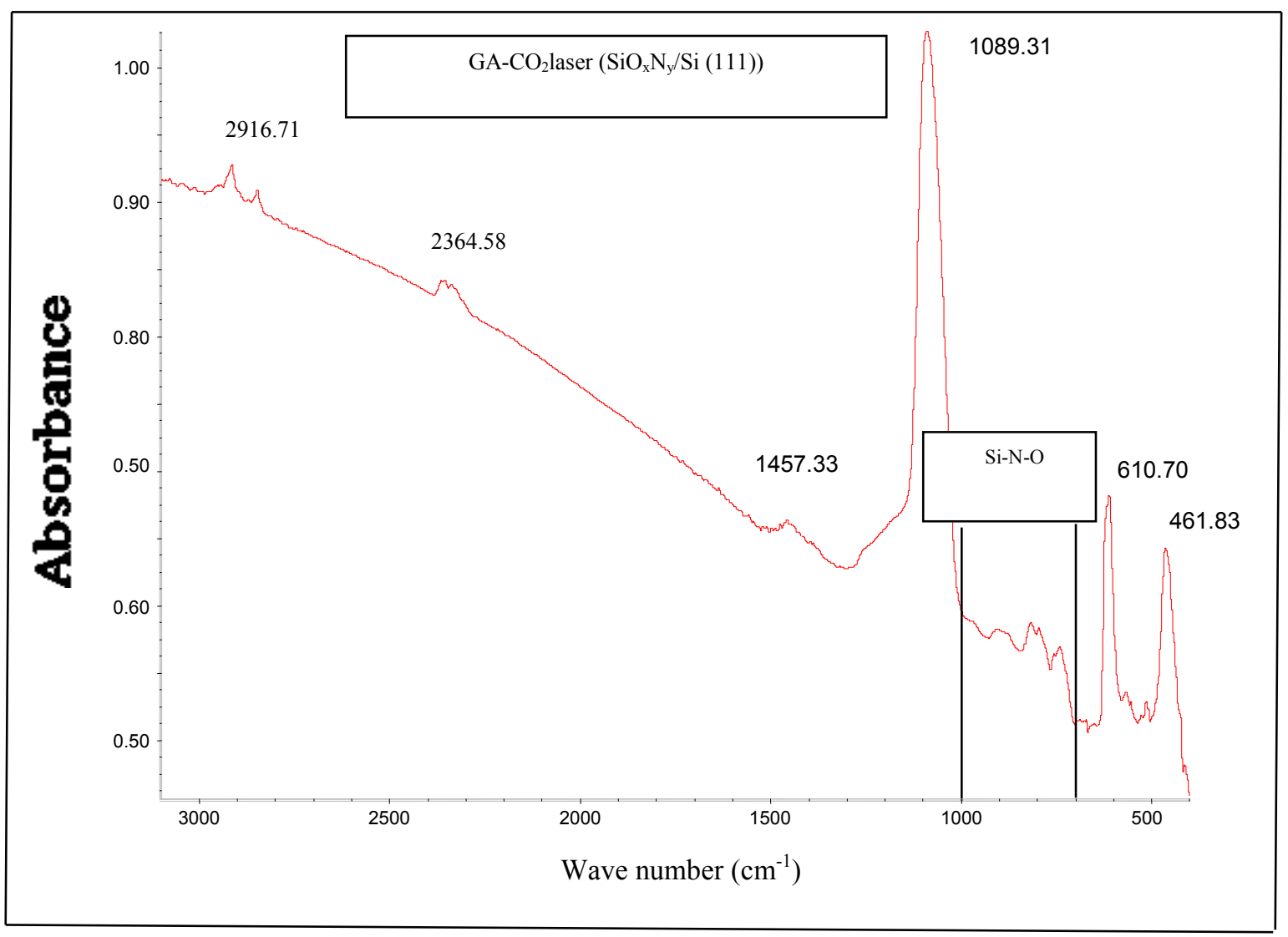

Fig. 2. Full FTIR absorption spectra for $\mathrm{SiO}_{\mathrm{x}} \mathrm{N}_{\mathrm{y}} / \mathrm{Si}(111)$ prepared at $750{ }^{\circ} \mathrm{C}$.

The absorption peaks assigned at 1457.33 and $1454.95 \mathrm{~cm}^{-1}$ for the two samples which is in the $1150-1540 \mathrm{~cm}^{-1}$ range, represents $\mathrm{N}-\mathrm{H}$ bending vibrations $[11,13]$ and the other peaks assigned at 2364.58, 2358.05 $\mathrm{cm}^{-1}$ and 2916.71, $2918.80 \mathrm{~cm}^{-1}$ are represent the Si-H and N-H stretching bonds. Such types of bond been reported by others in the bands 2000$2400 \mathrm{~cm}^{-1}[13-15]$ and 2500-4000 $\mathrm{cm}^{-1}$ wave numbers [12,13] with that of the absorption peak at $\sim 611 \mathrm{~cm}^{-1}$ is related to the saturated Si-Si bonds. 


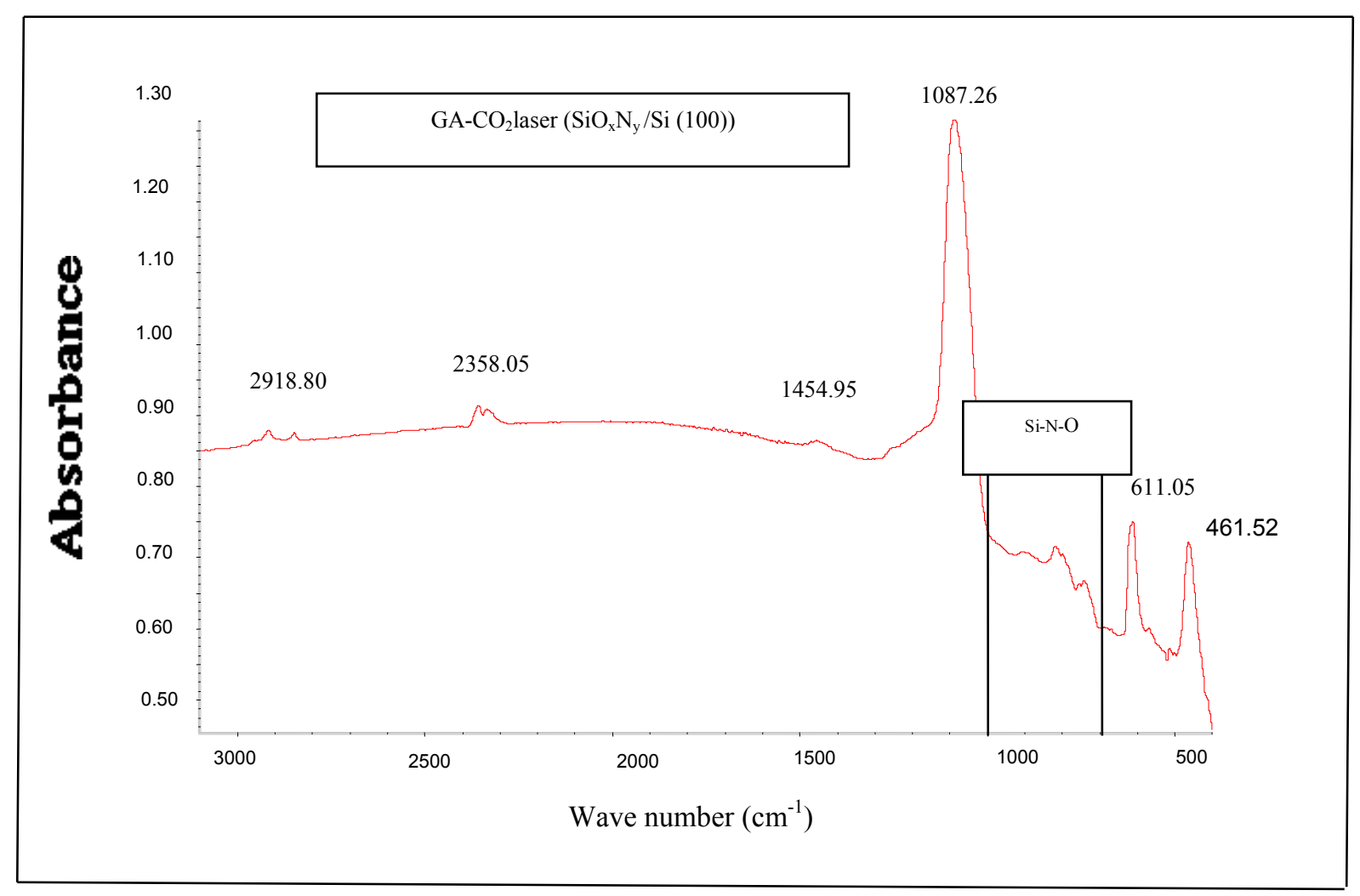

Fig. 3. Full FTIR absorption spectra for $\mathrm{SiO}_{\mathrm{x}} \mathrm{N}_{\mathrm{y}} / \mathrm{Si}(100)$ prepared at $750{ }^{\circ} \mathrm{C}$.

All the peaks related to $\mathrm{SiO}_{\mathrm{x}} \mathrm{N}_{\mathrm{y}} / \mathrm{Si}(111)$ are also appears for $\mathrm{SiO}_{\mathrm{x}} \mathrm{N}_{\mathrm{y}} / \mathrm{Si}(100)$ thin films spectrum, but with a small shift to a lower or upper wave number as shown in Table 1. These differences may be due to the change in films composition, this mean that the position of the peaks depends on the composition of the films and not on the silicon wafer crystallographic orientations. The concentration of hydrogen bonds for the two samples were estimated from the following formula [15]

$$
N=\frac{10^{7}}{K} \cdot \frac{A}{t}
$$

where $\mathrm{K}$ is the absorption cross section, $7.4 \cdot 10^{-18} \mathrm{~cm}^{2}$ for the $\mathrm{Si}-\mathrm{H}$ bond and $5.3 \cdot 10^{-18}$ for the $\mathrm{N}-\mathrm{H}$ bond [16], $\mathrm{A}$ is the area in the spectrum under the absorption peak, and $\mathrm{t}$ is the film thickness in nm. Fig. 4 show the both bonding types, obtained from FTIR spectrum for the two different samples under investigation.

Table 2, Shows hydrogen in bond concentration for both silicon and nitrogen for the two as grown films. Observed the lower density for $\mathrm{SiO}_{\mathrm{x}} \mathrm{N}_{\mathrm{y}} / \mathrm{Si}(100)$ films, more it preferable in using for ultra large-scale-integrated [17].

Fig. 5 shows the high frequency $(1 \mathrm{MHz}) \mathrm{C}-\mathrm{V}$ characteristics of the two samples. Calculations using rule $0.9 \mathrm{C}_{\mathrm{acc}}[18]$ generates as the flat-band voltages $\left(\mathrm{V}_{\mathrm{FB}}\right)$ to be equal to 5.4 and $-1.3 \mathrm{~V}$ respectively for $\mathrm{SiO}_{\mathrm{x}} \mathrm{N}_{\mathrm{y}} / \mathrm{Si}(111)$ and $\mathrm{SiO}_{\mathrm{x}} \mathrm{N}_{\mathrm{y}} / \mathrm{Si}(100)$. 


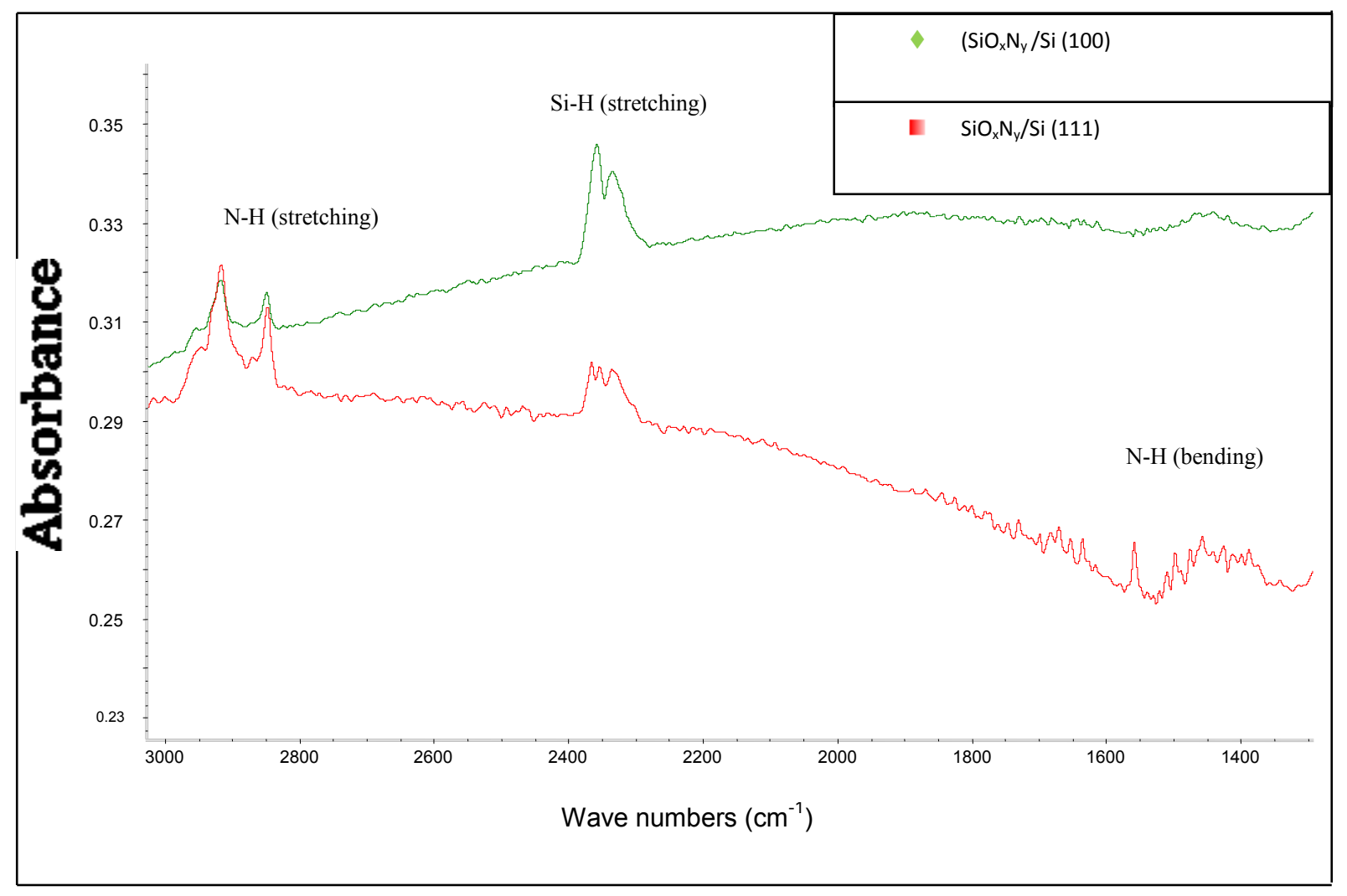

Fig. 4. Analysis of the hydrogen concentration in two kinds of $\mathrm{SiO}_{\mathrm{x}} \mathrm{N}_{\mathrm{y}}$ films, in FTIR spectra.

Table 2.Total bonded hydrogen content in different silicon substrate.

\begin{tabular}{|c|c|c|c|}
\hline $\begin{array}{c}\text { Silicon } \\
\text { Substrate }\end{array}$ & $\begin{array}{c}\text { Si-H } \\
\text { Stretching } \\
\text { Bond }\end{array}$ & $\begin{array}{c}\mathbf{N} / \mathbf{c m}^{\mathbf{3}} \times \mathbf{1 0}^{\mathbf{2 9}} \\
\begin{array}{c}\text { N-H } \\
\text { Stretching } \\
\text { Bond }\end{array}\end{array}$ & $\begin{array}{c}\mathbf{N} / \mathbf{c m}^{\mathbf{3}} \times \mathbf{1 0}^{\mathbf{2 9}} \\
\text { Bending } \\
\text { Bond }\end{array}$ \\
\hline Si (11) & 5.3 & 9.1 & 7.9 \\
\hline Si (100) & 8.5 & 4.4 & 3.2 \\
\hline
\end{tabular}

The larger shifts of the $\mathrm{V}_{\mathrm{FB}}$ towards the negative side silicon substrate $\mathrm{Si}(111)$ sample represent the higher intensity of hydrogen impurity as well as the generation of oxide defect. The area under the curves for Si-O peaks in the two samples found to be equal to 49.085 and 35.422 for $\mathrm{Si}(111)$ and $\mathrm{Si}(100)$ substrates respectively, and therefore the generation of oxide defect close to the interface region, gives a positively charged cases, as indicated by the negative shift direction [19]. The film thicknesses $(t)$ were determined by using the following formula [20]: 


$$
\frac{C_{i}}{a}=\frac{E_{o}}{t}
$$

Values of $(a)$ is the contact crossest area, $C_{i}$ is the capacitance in strong accumulation and $\left(\varepsilon_{0}\right)$ is the vacuum permittivity has a constant value $\left(8.85 \times 10^{-12} \mathrm{~F} / \mathrm{m}\right)$ and assumption of a dielectric constant $\varepsilon_{\mathrm{SiOxNy}}$ as $(\sim 4.91)$, found for the sample in the same condition deposition from the C-V characteristics [21], values of $19.2 \mathrm{~nm}$ and $17.2 \mathrm{~nm}$ for $t$ were found for $\mathrm{Si}(111)$ and $\mathrm{Si}(100)$ substrate coated film. In order to calculate the density of interface state $\left(D_{i t}\right)$ from the flat-band voltage condition of C-V characteristics, the Lehovec's method is used [22]. According to this method, $\mathrm{D}_{\mathrm{it}}$ can be calculated by using the following formula:

$$
D_{i t}=\left[\left(C_{0}-C_{F B}\right) C_{F B} / 3(\delta C / \delta V)_{F B} q K T A\right]-\left\lfloor C_{0}^{2} /\left(C_{0}-C_{F B}\right) A q^{2}\right\rfloor
$$

where $\mathrm{C}_{\mathrm{O}}$ is the capacitance of accumulation region, $\mathrm{C}_{\mathrm{FB}}$ is the flat-band capacitance, $\mathrm{A}$ is the electrode area, $\mathrm{k}$ is the Boltzmann's constant, $\mathrm{T}$ is the absolute temperature, $\mathrm{q}$ is the electronic charge, and $(\delta \mathrm{C} / \delta \mathrm{V})_{\mathrm{FB}}$ is the flat- band slope. The $\mathrm{D}_{\mathrm{it}}$ calculated in this work for the two samples were found to be $\left(1.4 \times 10^{13}\right.$ and $\left.1.57 \times 10^{13} \mathrm{ev}^{-1} \cdot \mathrm{cm}^{-2}\right)$ for sample1 and Sample 2 respectively. However the high contain nitrogen with that of extremely low hydrogen content for such samples under investigation allows it to have a high dielectric constant as well as a low trap density.

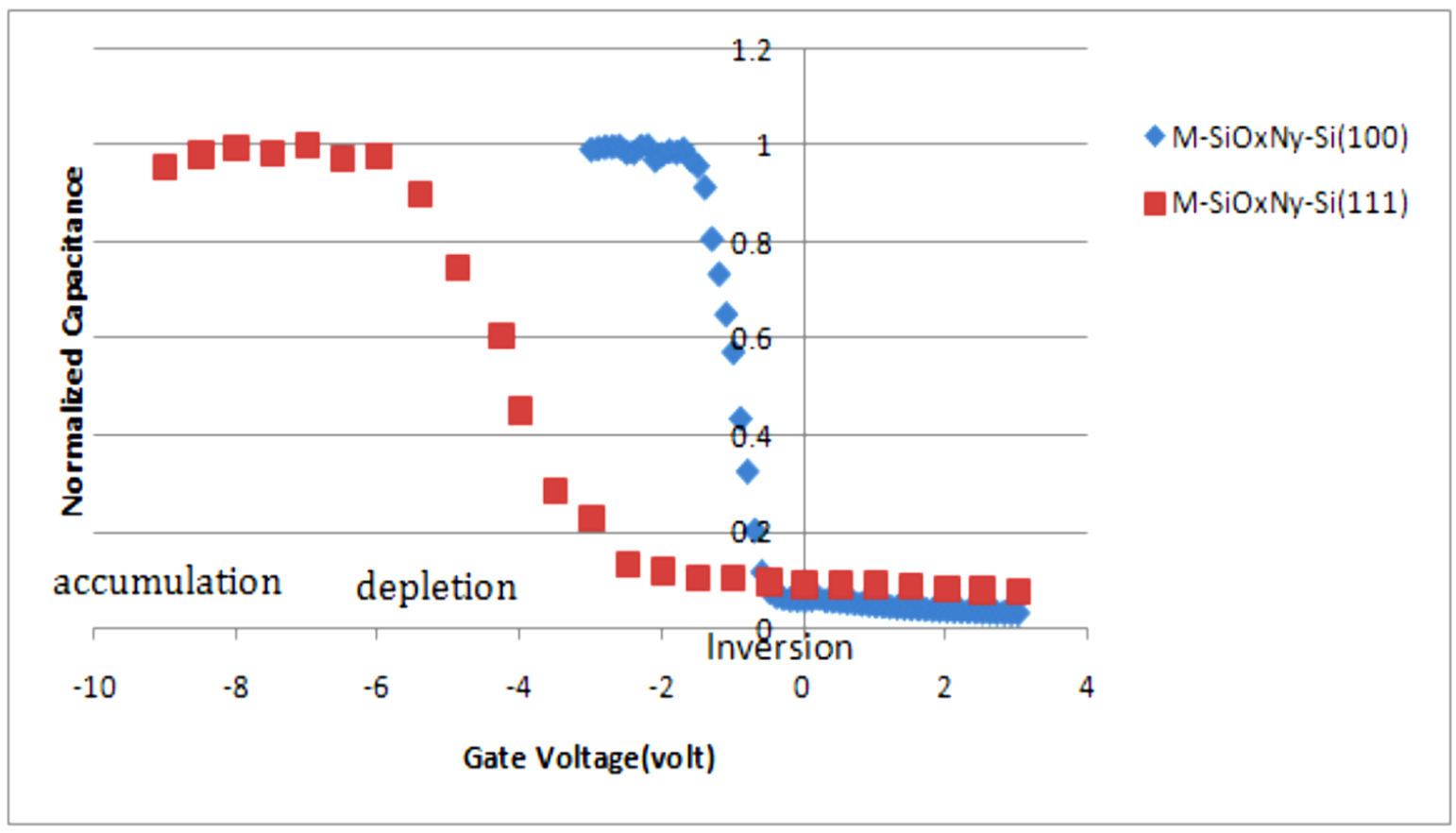

Fig. 5. $1 \mathrm{MHz} \mathrm{C}-\mathrm{V}$ traces for M-silicon oxynitride- Si devices. 


\section{CONCLUSION}

In summary, glass assisted $\mathrm{CO}_{2}$ laser growing in High purity mixture of $\mathrm{NH}_{3}$ and $\mathrm{O}_{2}$ gases results a surface coated $\mathrm{SiO}_{\mathrm{x}} \mathrm{N}_{\mathrm{y}} / \mathrm{Si}$ films. Through studying the crystallographic orientations of silicon it was found that the chemical bonding configuration of films depend on the composition which growed through the deposition and not on the silicon substrate. Also the impurity like ( $\mathrm{Si}-\mathrm{H}, \mathrm{N}-\mathrm{H})$ and oxide defect on $\mathrm{SiO}_{\mathrm{x}} \mathrm{N}_{\mathrm{y}} / \mathrm{Si}(111)$ much than $\mathrm{SiO}_{\mathrm{x}} \mathrm{N}_{\mathrm{y}} / \mathrm{Si}(100)$. Thicknesses of $\mathrm{SiO}_{\mathrm{x}} \mathrm{N}_{\mathrm{y}}$ thin films are depend on the oriented silicon wafers. This is agreement with the well- known fact that the rate of the growth of film is faster with (111) oriented wafers than with (100) oriented because they have different the available bonds per unit area on the silicon surfaces. The defect creation is resulting in the substrate surface during growth, which gives rise to an increase in the density of interface state.

\section{Acknowledgements}

The author wishes to express her appreciation to Dr. Yousif M. Hassan for his valuable supported, Prof. Dr. Mustafa S. Omar for reading the manuscript and college of science in the university of Salahaddin- Erbi, Iraqi Kurdistan in IRAQ for the financial support.

\section{References}

[1] N. Konofaos, E. K. Evangelou, Sci. Technol. 18 (2003) 56-59.

[2] F. Rebib, E. Tomasella, M. Dubois, J. Cellier, T. Sauvage, M. Jacquet, Thin solid films 515 ( 2007 ) 3480-3487.

[3] F. Rebib, E. Tomasella, V. Micheli, C. Eypert, J. Cellier, N. Laidani, Opt. Mater. 31 (2009) 510-513.

[4] M. Bedjaoui, B. Despax, Thin solid film 518 (2010) 4142-4149.

[5] F. Rrebib, E. Tomasella, V. Micheli, C. Eypert, J. Cellier, N. Laidani, Opt. Mater. 31 (2009) 510-513.

[6] S. H. Mohamed, Physica B 406 (2011) 211-215.

[7] Y. Liu, I. K. Lin, X. Zhang, Mat. Sci. Engineering A 489 (2008) 294-301.

[8] D. V. Tsu, G. Lucovsky, M. J. Mantini, Phys. Rev. B 33 (1986) 7069-7076.

[9] J. A. Diniz, P. J. Tatsch, M. A. A. Pudenzi, Appl. Phys. Lett. 69 (1996) 2214-2215.

[10] T. Maruyma, T. Shirai, Appl. Phys. Lett. 63 (1993) 611-613.

[11] V. P. Tolstoy, I. V. Chernyshova, V. A. Skryshevsky, Hand book of infrared spectroscopy of ultra thin films, A John, Wiley and Sons, Inc., (2003).

[12] W. L. Scopel, M. C. A. Fantini, M. I. Alayo, I. Pereyra, Thin Solid Films 413 (2002) 59-64.

[13] F. Giorgis, C. F. Pirri, E. Tresso, Thin Solid Films 307 (1997) 298-305.

[14] R. K. Pandey, L. S. Patil, J. P. Bange, D. R. Patil, A. M. Ahajan, D. S. Patil, D. K. Gautam, Opt. Mater. 25 (2004) 1-7. 
[15] L. S. Patil, R. K. Pandey, J. P. Bange, S. A. Gaikwad, D. K. Gautam, Opt. Mater. 27 (2005) 663-670.

[16] H. J. Schliwinski, U. Schnakenberg, W. Windbrache, H. Neff, P. Lange, J. Electrochem. Soc. 139 (1992) 1730-1735.

[17] J. X. Zhang, H. Cheng, Y. Z. Chen, A. Uddin, Shu Yuan, S. J. Geng, S. Zhang, Surface and coating technology 198 (2005) 68-73.

[18] D. K. Schroder, Semiconductor Material and Device Characterization, John-Wiley \& Sons, Inc. (NJ, USA) (2006), Ch.6, 328.

[19] S. M. Sze, K. K. Ng, Physics of Semiconductor Devices, $3^{\text {rd }}$ ed., John Willy \& Sons Inc., (2007).

[20] E. H. Nicollian, J. R. Brews, MOS (Metal Oxide Semiconductor) Physics and Technology, John Wiley and Sons, (2003).

[21] M. M. Ismael, Characteristics of $\mathrm{SiO}_{x} \mathrm{~N}_{y}$ Thin Films Prepared by $\mathrm{CO}_{2}$ Laser, Msc. Thesis, Salahaddin University-Erbil, (2010).

[22] S. M. Sze, Physics of Semiconductor Devices, second ed.,Wiley/Interscience, New York, (1981). 